\title{
A EXTRAPOLAÇÃO DAS RELAÇÕES VIRTUAIS EM BLACK MIRROR
}

\author{
Marcelo Santos da Rosa ${ }^{1}$ \\ Rosângela Fachel de Medeiros ${ }^{2}$
}

\begin{abstract}
Resumo: A contemporaneidade está permeada e norteada pela volatilidade das relações virtuais, que fazem com que as relações humanas, sociais e pessoais se transformam a todo instante. O sucesso da série britânica Black Mirror (2011-presente) está relacionado à maneira inovadora e surpreendente de sua narrativa em abordar o cotidiano dessas transformações, acompanhando a trajetória de personagens que estão imersas em ambientes e relações mediadas pelas relações tecnológicas. Nos episódios "Be Right Back" (2013) e "Nosedive" (2016), há personagens profundamente marcadas por relações humanas em redes sociais - a primeira consegue contatar o marido morto por meio das marcas deixadas por este em suas redes, enquanto a segunda vive em um mundo alienado por relações virtuais que determinam o caráter de seus usuários pessoalmente. Neste trabalho, buscamos relacionar as vivências dessas personagens com a realidade atual, na perspectiva de entender como as relações virtuais impactam o modo de vida das pessoas e a que isso pode levar. As reflexões despertadas pela série, que problematiza e extrapola o que se conhece hoje por rede ou conexão social e expande-se para suas implicações na vida das personagens, serão discutidas a partir de teorias da cibercultura (SANTAELLA; LEMOS), e de suas articulações com questões como virtualidade e imersão interativa.
\end{abstract}

Palavras-chave: Black Mirror. Cibercultura. Redes sociais.

Abstract: Contemporaneity is permeated and guided by the volatility of the virtual relations, which transform the human, social and personal relations all the time. The success of the British TV series Black Mirror (2011-present) is related with the innovative and surprising way of its narrative approach of daily life regarding to these transformations. The TV series follows the trajectory of characters who are immerse on settings and relations mediated by technological relations. On the episodes "Be Right Back" (2013) and "Nosedive" (2016), there are characters who are deeply touched by human relations on social networks - the first character is able to get in touch with her dead husband through his marks left on his social medias, while the second one lives in an alienated world where virtual relations impacts on the character of its users in person. In this work, we aim to relate the lives of these characters with the real life reality, in the perspective of understand how virtual relations impact on the way of living of people and what are the results of it. The reflections allowed by the series, which problematize and extrapolate what we now know as social network or connection and it implicates on its characters' lives, will be discussed through cyberculture'stheories (SANTAELLA; LEMOS), and its articulations with questions as virtuality and interactive immersion.

Keywords: Black Mirror. Cyberculture. Social Networks.

\footnotetext{
${ }^{1}$ Universidade Regional Integrada do Alto Uruguai $e$ das Missões (URI). E-mail: Marcelo.santosdarosa@gmail.com

${ }^{2}$ Universidade Regional Integrada do Alto Uruguai e das Missões (URI). E-mail: fachel@fw.uri.br
} 


\section{Reflexões acerca das relações entre arte e sociedade}

"O que seja usado como peça de uma máquina, é, de fato, uma peça dessa máquina". Norbert Wiener

Inovações tecnológicas despertaram, no homem e ao longo dos tempos, a surpresa e o espanto. Surpresa, enquanto atitude positiva, pois a criação ou descoberta de um produto que pudesse substituir uma atividade humana e trazer comodidade ao homo sapiens sapiens era, em geral, celebrada. Espanto pois, ao satisfazer um capricho ou auxiliar processos dificultosos, esses objetos tornavam o homem um pouco menos útil, pois algo inanimado poderia realizar o trabalho de seu corpo, com ou mesmo sem o auxílio do ser pensante.

Foi assim com qualquer meio de transporte, com as máquinas produtoras de calçados, alimentos e outros, o telefone, o elevador, o computador. Nos anos 1950, o cientista Norbert Wiener (1968) se propôs a refletir sobre as inovações tecnológicas que surgiam e quais suas implicações na sociedade. Descrevendo o impacto de objetos de comunicação, do elevador, as invenções movidas à eletricidade etc., ele faz um parâmetro sobre como o homem se reflete em meio ao uso de novas tecnologias da época.

O pensador demonstrava sua preocupação de que a ascensão das máquinas traria um perigo, não das máquinas em si, mas do uso humano delas (WIENER, 1968, p. 180). Essa preocupação do autor se alastra na forma como o homem passava a se perceber no advento de invenções das quais o humano poderia talvez não assumir total controle. Sua preocupação de via dupla acarretava em como a máquina alteraria a atitude humana e como o homem usaria seus semelhantes como se fosse uma parte da máquina.

De certa forma em sintonia com as reflexões sobre as modificações na sociedade e como o homem as encara, Colvara (2007) comenta sobre a tecnocultura que se criou. Para a autora, a sociedade alterou os hábitos humanos e trouxe uma falsa ilusão de que ele supera a si próprio. Em meio a essas modificações, o homem busca, por meio de suas criações, a superação de um vazio que a pós-modernidade trouxe. "As regras e o mundo passam a ser determinados 
pela máquina", diz Corvara, "as verdades são produzidas por ela, mesmo que operadas pelo homem". (CORVARA, 2007, p. 113).

Tem-se uma realidade alterada pela criação, pela tecnologia, pela pósmodernidade, em que as relações se estabelecem de forma diferenciada. Nessas novas relações e nessa nova configuração de sociedade, o humano e as regras básicas das quais conhecia são transformadas, problematizando mesmo o senso de verdade, de realidade. Nesse novo momento da configuração social, o homem fica em segundo plano e "é dada à máquina essa capacidade de governabilidade da identidade, das emoções" (idem, p. 112).

As reflexões expressas pela ciência se imbricam em um repensar de modelos sociais que são alterados, transformados, criados e recriados a todo instante. Essa volatilidade da condição social e de suas relações são preocupações tendo em vista os impactos que causam na vida, no status quo, e no impacto que podem deixar tanto para as gerações que se transformam nesse meio, quanto nas que chegam e nascem já em um meio diferente ao qual a humanidade esteve habituado, sem tantas transformações.

Preocupações acerca do impacto de inovações tecnológicas na vida humana não são exclusivas da ciência, sendo a arte uma das manifestações humanas que mais as tem problematizado. Aliás, a arte a tem problematizado por ser vertida no cerne das relações humanas. Adorno (1997) atesta que a arte possui um caráter duplo: ela é ao mesmo tempo autônoma e derivada de um caráter social. A arte possui sua própria autonomia, mas ela parte de um contexto de realidade importante no qual se estabelece enquanto arte. Mesmo que a arte assuma ser um objeto que parta da imaginação, sua presença ainda transparece, de alguma forma, no plano da realidade.

A reflexão de Adorno faz eco com reflexões de Eagleton (1990) acerca do berço da arte. "Nós podemos ver algo porque isso está presente em nós; mas o que geralmente não conseguimos ver é o que possibilitou essa presença em primeiro lugar" (EAGLETON, 1990 p. 289; tradução livre para o trabalho). Mesmo que a arte parta para um plano inumano, ou longe do tempo e do espaço atual, sua manifestação partiu de um lugar humano, o lugar de onde o escritor, o pintor, o dançarino, o fotógrafo, o roteirista, o diretor partiu para compor sua arte. 
Dessa forma, a arte percorre um percurso estreito entre realidade-fiç̧ãorealidade. Ela parte da realidade, assume uma característica de ficção ao ser constituído por recursos estéticos de múltiplas formas, mas se volta para a realidade quando atinge as pessoas que têm contato com ela. É um esquema que se repete e que existe porque a arte é feita de humanos para humanos.

Com esse pensamento, observam-se que objetos artísticos têm se voltado para a reflexão sobre as novas relações sociais permitidas por tecnologias diversas. Um desses objetos artísticos é a série Black Mirror, exibida com exclusividade na internet por meio da plataforma Netflix, na qual é possível assistir a filmes, séries e documentários, alguns exibidos primeiramente em outros contextos multimídias (televisão, cinema), e outros produzidos especialmente para a plataforma.

Black Mirror é uma série que vem se destacado por problematizar experiências humanas em virtude e por causa de tecnologias. A série apresenta um universo paralelo, ambientado geralmente no futuro, em que põe em cheque a relação homem-tecnologia. Ela apresenta episódios independentes, que se relacionam apenas por se tratarem daquela relação.

O trabalho volta-se para os seus objetivos principais, que são os de analisar dois episódios de Black Mirror que problematizem relações sociais - especialmente as que ocorrem virtualmente - a fim de identificar elementos crítico-reflexivos presentes na obra; e o de relacionar reflexões expressas em Black Mirror que se relacionam a vivências sociais e virtuais típicas da atualidade.

Black Mirror, ao abordar a realidade das novas relações e das extrapolações das relações humanas e virtuais, brinca com a realidade. Essa brincadeira surge pela aproximação estreita que a série propõe entre a realidade e o futuro desta realidade. A série traz o futuro como uma possibilidade imediata, como se fosse a própria realidade na qual estamos sucumbindo. Isso para levar à reflexão.

Essa brincadeira da realidade exposta na tela tem sido acompanhada por uma reviravolta social no que consideramos como realidade de fato. Marcia Tiburi (2011) apresenta uma explanação a esse respeito, ao comentar que o fim da ideia de que 0 homem é a medida de todas as coisas contribui para que o que a tela mostre entre em foco. "A grande tela não seria apenas a tela grande, mas aquela que, com a antecipação do adjetivo "grande", teria a garantia do verdadeiro" (TIBURI, 2011, p. 136). 
A fim de compreendermos como se constituem as relações em Black Mirror, pensa-se primeiro nas reflexões de Santaella (2007), autora que determina que as imagens da subjetividade na atualidade são multiformes, heteróclitas, descentradas, instáveis e subversivas. Para a autora, há uma busca, nas novas relações cibernéticas, em fugir de uma constante para o próprio "eu". Por isso, ocorre uma multiplicidade de identidades, muitas delas apenas simuladas.

Essas vivências identitárias são simuladas e se relacionam a termos como "realidade virtual" e "tempo real", em que a própria condição de vida é problematizada. Afinal, vive-se uma identidade que transita no real e no virtual, ou tratam-se de múltiplas identidades, algumas delas forjadas no mundo virtual? Santaella propõe novas reflexões acerca disso.

O advento das mídias, multiplicadores da mobilidade, nas formas de viagens vicárias que propiciam, distancia os indivíduos dos locais imediatos de sua vida cotidiana. Assim, o ser humano é continuamente confrontado com novas possibilidades pelas mudanças constantes de horizontes e pontos de referência. (SANTAELLA, 2007, p. 94).

A autora admite que criam-se personas on-line, seja para jogos, seja para novas vivências, as quais ocorrem no ambiente virtual. Apresenta-se, portanto e no mínimo, mais de uma identidade, a estabelecida em contextos "reais" e a(s) vivenciada(s) virtualmente. "Características fundamentais da modernidade [...] encontram-se no transitório, fugitivo, contingente" (SANTAELLA, 2007, p. 106) entram em confronto com o que havia anteriormente, que se configurava de forma fixa, no plano considerado real.

Numa perspectiva de entender os processos, Santaella diferencia dois termos importantes, que são cultura das mídias e cibercultura (SANTAELLA, 2003): a diferença se estabelece essencialmente no ponto em que a cultura das mídias se pautava na transmissão de informações/conteúdos, enquanto na cibercultura ocorre uma troca mais dinâmica. As informações se espalham e o sujeito está, também, transitando. O usuário de mídias, não mais receptor, agora conversa com telas, altera seus hábitos de consumo, em um contexto de aceleração e preocupação com a humanização dos processos (p. 82).

Sobre a cibercultura, Santaella assim escreve: 
A natureza dessa cultura é essencialmente heterogênea. Usuários acessam o sistema de todas as partes do mundo, e, dentro dos limites da compatibilidade linguística, interagem com pessoas de culturas [...]. Materializa-se em estruturas de informação que veiculam signos imateriais, feitos de luses e bytes, signos evanescentes, voláteis, mas recuperáveis a qualquer instante (SANTAELLA, 2003, p. 103-104).

Tendo cibercultura como um termo-chave para entendermos as relações que ocorrem, buscamos as palavras de Lemos (2016) para entendermos melhor do que se trata. Para o autor, existe um sonho de que a cibercultura seja "uma nuvem de conexão pairando sobre nossas cabeças, podendo ser acessada de qualquer lugar, andando, sentado na praça ou dentro do ônibus" (idem). Esse sonho é chamado pelo autor como "mobilidade e conexão".

Mobilidade e conexão são fatores que se apresentam de forma bastante delineada nos episódios analisados de Black Mirror neste artigo. Os episódios são Be Right Back e Nosedive, os quais são, respectivamente, o primeiro episódio da segunda temporada e o segundo o primeiro episódio da terceira temporada. Os episódios, como os outros da série, não são relacionados.

\section{Análise dos episódios Be Right Back e Nosedive}

\section{BE RIGHT BACK}

O título do episódio Be Right Back apresenta duas interpretações. Primeiramente, parte de uma expressão típica da internet na comunicação on-line de falantes de língua inglesa. Há, desde o título do episódio, a intenção de aproximar a série de elementos do cotidiano virtual do público que assiste. Em seguida, em uma dubiedade, apresenta também o significado de alguém que "volta logo", o qual é irônico ao ser relacionado com o "retorno" no roteiro do episódio.

O roteiro traz Martha como protagonista, uma mulher que acaba de perder seu esposo, sendo ele bastante jovem. A mulher cai em tristeza, pois o amava intensamente, tendo o sentido de sua vida posto em cheque com a perda do cônjuge. Fato importante se de tecnologias disponíveis, ela passa a ter contato novamente com ele. 
Os contatos são feitos por telefone, uma vez que a voz de seu ex-marido ficou registrada na rede e foi utilizada para a reconstrução dele por meio auditivo. Mas os contatos via telefone e a troca de mensagens não são suficientes para Martha, que sente o desejo de mais. Após indicação de uma amiga, ela utiliza nova tecnologia para trazer seu marido "de volta" à vida. O retorno do marido é marcado pelas impressões que ele deixou na internet, especialmente nas redes sociais que utilizada. Mas esse retorno é diferente, pois ele retorna frio, marcado por atitudes quase robóticas.

Temos em cena um novo Franknstein, uma criatura que não é um ser vivo, mas aparenta como um. Ele é trazido à vida por meio de impressões deixadas por sua existência real em contextos virtuais, que problematizam as relações que são feitas nas redes sociais. Martha não se relaciona com o ex-marido, que está morto, mas com as impressões que este deixou, em vida, em suas redes sociais.

O dr. Frankstein é a própria rede; é onde as pessoas deixam suas imagens, sua voz, a forma como escrevem e partilham suas ideias. É por meio dela que é possível a recriação de um ser real em uma existência corpórea. Para a recriação de Ash, tudo o que ele partilhava em vida foi utilizado para sua recriação. Tem-se uma identidade virtual, apenas através dela a recriação foi possível. O estranhamento marca a relação entre Martha e Ash, não o amor de quando ambas as personagens eram vivas no plano real.

\section{NOSEDIVE}

O título do episódio é tomado pela expressão "nosedive", que indica a queda inesperada e muito forte de um objeto. Em uma analogia, o título se refere à vida de Lacie, a protagonista, que desmorona de forma bastante abrupta, motivada por relações virtuais que são expressas em seu mundo no plano real, sendo que uma implica na outra.

Lacie vive uma vida em que busca agradar a todos em suas relações virtuais e no plano real, relação estabelecida por meio de um aplicativo. A caminho de uma festa em que receberia notas positivas para si nesse aplicativo, Lacie acaba sofrendo o oposto e tem sua nota derrubada, o que dificulta sua trajetória a partir de então no episódio. 
As relações virtuais em Nosedive são para recebimento de notas. Isso implica também na vida no plano real das personagens, cujas ações são para não receberem notas negativas. Xingamentos, crimes e descortesia são motivos para recebimento de notas baixas, enquanto elogios, civismo e bom comportamento são razões para boas notas. Há uma alienação no sentido de que deve-se agradar ao outro, fazer o que parece bonito aos olhos dos outros.

$\mathrm{Na}$ busca por boas notas, as pessoas agradam a todos, simulam sentimentos, mentem sobre o que pensam uns sobre os outros, sorriem o tempo todo para serem bem vistos. A vida no contexto real se volta para o sucesso no plano virtual. Não mais o real importa, ele é apenas um caminho simulado para a verdadeira visão que as pessoas terão uma das outras, e essa visão é oferecida por meio de uma nota que a pessoa recebe virtualmente.

As relações apontadas por Black Mirror são de extrapolação virtual para a extrapolação do real, que é motivado pela virtualidade. As aparências funcionam mais e melhor que as atitudes sinceras que as personagens poderiam exprimir. As personagens que apresentam atitudes autônomas possuem notas baixas, são vistas com maus olhos pelas outras. Há uma alienação para que todos ajam de foram parecida, na busca interminável por serem bem avaliados no aplicativo.

\section{Reflexões finais}

A cibercultura é marcada por um sonho de mobilidade e conexão. Esse sonho é expresso em Black Mirror, série em que personagens estão conectadas o tempo todo, e quando deixam de se conectar, ainda é possível serem recriados virtualmente pelas impressões que deixaram. A série oferece a representação das intensas relações sociais e virtuais que a tecnologia oferta.

Percebe-se na personagem de Martha a busca pelo que se foi por meio da tecnologia. As impressões deixadas pelo ex-marido apontam para o quanto as pessoas têm se aprofundado em contextos virtuais, ao ponto em que seria possível recriar a si próprio a partir de experiências na rede. As marcas deixadas pelo ser humano em ambientes da rede são profundas e capazes de uma criação a partir delas. A tecnologia apresenta sua própria força criadora e torna-se um ser criador. 
Além disso, a presença de Ash na vida de Lacie torna-se fria, distante. Reconhecendo que o Ash criatura é fruto das impressões na rede, entende-se que as relações que Ash teve em vida e que ficaram marcadas na rede eram relações frias, distantes, incapazes de serem humanas o suficiente. A série critica a extrapolação das redes na atualidade, que oferta relações próximas, mas ao mesmo tempo frias e distantes.

Em Nosedive, há a formulação da vida em função da rede. O que ocorre virtualmente na vida de Lacie é o que determina como a vida real dela deverá ser. Números online são mais importantes que as próprias relações que os determinam, e quando a pessoa consegue libertar-se das correntes virtuais que as prendem a um sistema, elas são vistas como seres inferiores, dignos de desprezo ou de temor.

Estabelecendo uma relação com o contexto atual da sociedade e suas relações sociais e virtuais, entende-se que a série pretende problematizar a atitude negativa com pessoas que não se encaixam em redes ou rótulos que a sociedade propõe. Há um espelho de uma sociedade que busca fazer com que todos os sujeitos ajam de maneira similar com o fim de se enquadrarem no próprio sistema.

Em ambos os episódios, as relações virtuais são extrapoladas, haja vista a necessidade de as personagens adaptarem suas vidas por causa do virtual. Nesse caso, a vida em plano real assume papel secundário, determinado por aquilo que é criado na rede - seja a rede criadora da pessoa que é amada ou fundadora da própria identidade da pessoa.

\section{REFERÊNCIAS}

ADORNO, Theodor. Aesthetic theory. Translated by: Robert Hullot-Tiedemann.New York: Continuum Books, 1997.

COLVARA, Lauren Ferreira. Tecnocentrismo: identidades múltiplas e nova subjetividade. In: Conexão: comunicação e cultura. Revista de Comunicação da Universidade de Caxias do Sul - v. 6, n. 11, jan.-jun./2007. Caxias do Sul: EDUCS, 2007.

EAGLETON, Terry. The ideology of the aesthetic. Oxford: Blackwell Publishers, 1990.

LEMOS, André. Cibercultura e Mobilidade: a Era da Conexão. In: Revista Razón y palabra,

$\mathrm{n}$.

42.

Disponível

em: 
<http://www.razonypalabra.org.mx/anteriores/n41/alemos.html>. Acesso em: 2 set. 2016.

SANTAELLA, Lúcia. Culturas e artes do pós humano: da cultura das mídias à cibercultura. São Paulo: Paulus, 2003.

. Linguagens líquidas na era da mobilidade. São Paulo: Paulus, 2007.

TIBURI, Marcia. Olho de vidro: a televisão e o estado de exceção da imagem. $2^{\mathfrak{a}}$. Ed. São Paulo: Editora Record, 2011.

WIENER, Norbert. Cibernética e sociedade: o uso humano de seres humanos. Trad. José Paulo Paes. São Paulo: Editora Cultrix, 2ª . Ed. 1968. 